\title{
WORKPLACE PEACE CONSTRUCTION THROUGH VERBAL AND NON- VERBAL COMMUNICATION IN THE UNIVERSITY OF CALABAR
}

\author{
Louisa Etebom Uwatt \& Alexander Essien Timothy \\ University of Calabar, Calabar, Nigeria
}

\begin{abstract}
The study investigated university workers' perception of the verbal and non-verbal communication variables that are important to workplace peace. Three research questions were posed. Questionnaires were used for data collection. The analysis was done using simple percentages. The results showed that for verbal communication, participants considered a rich vocabulary and good diction as very important to workplace peace. For non-verbal communication, politeness and words of endearment were rated most important to workplace peace.
\end{abstract}

Keywords: civility, communication, verbal and non-verbal, peace, workplace Introduction

Workplaces differ. As workplaces differ, so does the language required to construct the atmosphere of peace in them. Our focus in this paper is the academic workplace and the language that could be deployed to create and sustain a culture of peace in the workplace. Since language is highly contextualised, language that is appropriate in one context may be inappropriate in another. Although language serves variety of purposes in formal and nonformal contexts (Eyang \& Edung, 2017, Eyang, 2016). A clear understanding of the context of discourse is important in negotiating workplace peace communication.

Our study is situated in the University of Calabar, Calabar in the Niger Delta geopolitical zone of Nigeria. Calabar is the capital of Cross River State. The main indigenous 
peoples are Efik, Ejagham, and Efut. Because of her metropolitan nature, Calabar has in her population people from other ethnolinguistic groups in Nigeria. They include Fulani, Hausa, Ibibio, Igbo, Ijaw, Yoruba, etc.. Besides, Cross River State is distinguished for her linguistic heterogeneity and credited to play host to over 200 indigenous ethnolinguistic groups (National Population Commission, 2006 and Udoh, 2003). However, the official language is English.

These diversities reflect in the university community of students, faculty, administrative and clerical staff, as well as many others who are engaged in different businesses in the university. The University of Calabar is, thus, a microcosm of the ethnolinguistic diversity that is evident in the Nigerian polity. Rodriguez (2006) acknowledges that "life in the workplace, like life elsewhere in a diverse and decentralized society, consists of a multitude of overlapping social interactions, where multiple linguistic transactions occur simultaneously, sometimes involving the same person or people.(p.1721).

The network of relationships in a multicultural university environment is evidently a fertile bed for conflict to propagate (Timothy, 2017; Timothy \& Uguma, 2017). Workplace conflict is likely to affect productivity and could render the systems dysfunctional. Managing conflict in the workplace, therefore, is not only essential for personal wellbeing, but also for industrial wellbeing.

One common denominator, despite the diversities, is language and, by implication, communication. Sapir (1963) describes language as the key to a people's heart. In other words, language unlocks the thoughts, emotions, perceptions, insights, intuitions and attitudes. Conflict and peace reside in the human heart and language can be deployed to 
minister either conflict or peace. Work place conflict can be the product of the interpersonal communication negotiated through language. Peace, similarly, can be constructed from the verbal and non-verbal narratives enacted in the workplace. This can be achieved through communication.

Communication as defined by Ghaith and Shaban(1994) is a universal process of encoding and decoding "thoughts, feelings, emotions, and attitudes through written, verbal, nonverbal, musical, and mathematical symbols." They add that the decoder's experiential background and shared cultural knowledge influence the decoding process.

Hence, Shedrack (2004) as cited in Adejimola (2009, p.005) suggests that: Communication is a non-adversarial, cheap method of preventing and removing conflict situations, quite within the grip of the parties. Once communication is lost, parties risk getting into deeper crisis that cannot be easily resolved.

Shedrack (2004) further acknowledges that most methods of conflict management, whether arbitration, mediation, or negotiation, depend on communication.

\section{Language of Peace}

What should be the attribute of language used in negotiating peace in the workplace? Research indicates that 80 per cent of all human communication is non-verbal (Mehrabian, 1969). Therefore, in the following sections, we shall explore non-verbal /paralinguistic language that peace speaks in the workplace, especially language of immediacy and civility. Language of immediacy and civility

Mehrabian (1969) conceptualized immediacy as behaviours that "enhance closeness to 
and nonverbal interaction with another" (p.203). Components of immediacy include eye contact, attentive body orientation, reduced physical distance, leaning forward, openness of posture, light touch to a nonthreatening body part, and relaxed posture (Mehrabian, 1967b, 1968, 1969, 1971b, 1972, 1981 - cited in Kelly, 2008). Immediate behaviours tend to reduce the social distance between persons (Turman, 2008). Besides, message receivers evaluate perceived immediate people as more likeable than non-immediate persons (Houser, Horan, \& Furier, 2008).

Civility, on the hand, is defined by Davetian (2009) as "the extent to which citizens of a given culture speak and act in ways that demonstrate a caring for the welfare of others, as well as the welfare of the culture they share in common" (p. 9). Civility could be "demonstrated through politeness, courtesy and an awareness of other people's rights, wishes, and feelings." (Weeks, 2011). Forni( 2002), however, adds that civility transcends mere " attitude of benevolent and thoughtful relating to other individuals; it also entails an active interest in the well being of our communities and even concern for the health of the planet on which we live" (p.9).

Similarly, in a survey of faculty, staff and students of University of Maryland, Baltimore, Aly, Brent, Chihos, Clark, Ghaziri, Mansdorf, and Mishler (2013) found that 82 per cent of respondents said it was important for them to function in a civil environment. They suggest that uncivil work conditions increase levels of burnout. In addition, the American Association of State Colleges and Universities (AASCU) has asserted that a civil environment was a necessity for academic freedom and critical to life in a democratic society (Bowman, 2011). 
Therefore, the principles of immediacy and civility inform our contextual exploration of some of the non-verbal peace dialogic strategies that could be deployed in the Nigerian university work. Such strategies include greetings, address, voice, smile, handshake and hug.

\section{Greetings}

Greetings are the exchange of customary social goodwill between or among people of a shared environment or culture. It is believed that "The seeds of civility can be planted in an organization by encouraging every employee to give their coworkers greetings befitting the professional nature of the work environment." (Moreno Valley College, 2013, p.17).

We can convey greetings verbally or non-verbally. Common greetings are Good Morning, Good Afternoon, Good Evening. The vernacular and/or Pidgin versions may be deployed in informal situations. Peers may use "Hi" or "hello." However, using such with one's elder or superior conveys disrespect, if not affront. In Nigeria, as in many other African cultures, the younger greet the elder first, and the junior greet the senior. However, seniors in rank who go out of their ways to greet their junior first, especially if the junior is older, speak the language of peace.

It is also common in greetings to append titles. The Efik add, "Mma" (Madam), for a female or "Ete" (Sir), for a male. People treasure highly such appendages to greetings and see them as evidence of good upbringing and respect. Within the academic community, where the lingua franca is English, the appendage of Prof or Doctor to greetings is highly esteemed. People feel offended sometimes if one omits the appropriate appendage.

The non-verbal component of greetings like curtsying is often more important than the 
voice greetings. Among the Efik and Igbos, for instance, a younger person greets the elder with a slight bow. The Yoruba prostrate before their elders, women kneel or touch their knees while greeting their elders. It is common to see people who, though, are not Yoruba, greet Yoruba elders with a touch to their knees. Cultural literacy is important in a multicultural environment like Nigeria, as it acquaints participants in the social intercourse with culturally appropriate responses (Timothy, 2017).

Equally important is the response to greetings. A smile, eye contact, a touch, and endearing remarks about the greeter are often the accompaniments to the culture of greetings. Consider this exchange between a young Efik woman and an elder.

Young woman: Emesiere oh, Ete (Good morning, Father/Sir)

Elder : Emesiere, ediye owo (Good morning, beautiful one).

\section{Address}

The way we address our colleagues can engender either peace or discord. In the University of Calabar, as in other Nigerian universities, lecturers prefer being addressed with their academic titles of either Dr or Prof. Whereas lecturers may address their peers in their first names; they would address their seniors or elders in their surnames. With one's peers, the appendages are rarely necessary. In fact, in Nigeria, it is frequently considered an affront to address one's superior by their first name. It is common for people to address their close associates as "my brother' or "my sister" even when they are not siblings. Such terms foster a sense of closeness, rapprochement, rapport, and endearment. Such ingredients eloquently flavour the language of peace. 
Language of Voice.

The tone of voice, the timbre, rhythm, the intonation, all combine to create an atmosphere of peace. "A soft answer," according to the bible, "turns away wrath" (Proverbs15:1, NKJV). The bible further states that a word well spoken is like choice silver in a vessel of gold. Bicki (2008) observes that paralinguistic cues like "loudness, pitch, timbre, rate, inflection, rhythm, and enunciation" often reveal emotional conditions. Differences in all relate to the expression of various emotions. Bicki reports also that experimental findings suggest that active feelings such as rage, are exemplified vocally by high pitch, fast pace, and blaring sound, while passive feelings such as despair, are portrayed by low pitch, retarded pace, and resonant sound. A voice that is well modulated to suit the occasion or purpose is one of the ways that peace can be communicated in the workplace. Thus, a joyous voice in a joyful situation and a sober voice in a sad occasion are some of the voice skills that could be employed to negotiate peace in the workplace

Language of Smile.

Even as innocent and as innocuous as it seems, a smile is capable of effacing conflict, ameliorating tension and restoring harmony. There is something contagious about a smile. A smile is a little tug at the edges of the mouth, but can spread a radiant beam from face to face, illuminating and animating a gloomy atmosphere. Rychlowska et al (2017, p. 1259) identify different types of smiles, one of which is functional smile which results in "... rewarding behavior, bonding socially, and negotiating hierarchy.” According to Heerey and Gilder (2019),

... both genuine and polite smiles are rewarding, relative to neutral faces. However, in 
states of high social need, polite smiles turn from mildly positive into negative social stimuli. This effect translates to real-world social decisions by reducing the frequency with which those anticipating social rejection respond to a social partner's polite smiles. Thus, the degree to which a social cue influences social decisions depends profoundly on the receiver's social state.... (p.16).

Schoenmakers (2014) puts it thus: "Although good conditions do make life and work easier for teachers, the human approach of respect and appreciation can never be underestimated....A big smile can do wonders." (p.63). In addition, research shows that even in the relationship between faculty and students, students liked teachers who smiled (Bıçk1, 2008, citing Bıçk1 and Gökkaya, 2004; Timothy \& Uguma, 2017).

\section{Listening.}

Listening is not only an act but also an art. The Bible states, "He who answers before listening, that is his folly and his shame." (Prov. 18:13). Listening is a conscious and a deliberate attention to sound stimuli. Besides, being one of the verbal language skills, it is also a nonverbal skill because it combines with certain postural variables to indicate to the communicators that the commuicatee is paying attention. If one is discussing with another, and the other is fiddling with their phones, it conveys to the speaker that the listener is not paying attention.

Pearson and Porath (2005) recommend that incivility in the workplace can be curtailed by improving individual competencies like conflict resolution, negotiation and listening. Also, Scales (2010) offers this nugget: "Respectful listening encourages respectful listening: if you want to be heard, listen" (p.17). UNESCO (1998) notes that "where people seek non- 
violent means to resolve conflict" such as "negotiation and persuasion, the art of listening and dialogue can be learned and practised"(p160).

\section{Handshake}

A handshake shows mutual respect and acknowledgement of the other. In the Efik and Ibibio cultures, younger ones offer both hands to their elders in a handshake. In offices, the junior often do the same with their seniors. Among the Hausa-Fulani culture, one touches ones' left breast after a handshake, a sign of goodwill, devotion and endearment. In some cultures, however (for example, among Muslims), men do not shake hands with women. Any insensitivity to such cultural restraints can gravely hinder peaceful coexistence in the workplace.

Although Western culture propagated in TVs tends to erode the observance of these social norms, especially among the youths, the elderly in Nigeria who value the status-quo still credit as civil people who observe those values in their workplace performances.

\section{The Hug}

The hug is a sign of close intimacy. There are two main types of hugs. There is the frontal hug, where both parties engulf each other in their arms in a warm embrace. It shows trust and gladness. It could be between people of the same sex or opposite sex. It could be between friends, parent and child, spouses, peers, siblings, between the elder and the younger, or between the superior and the subordinate.

The second type of hug is sideways. An Igbo proverb says that a handshake that extends beyond the elbow is trouble. It means one should not breach another's personal space. The Efik and the Ibibio have a saying that hugging another's wife should not exceed the elbow. 
Decorum, among the Efik and the Ibibio, for instance, demands some restraint when one hugs a woman (married or single) other than one's close relative. Therefore, such hugs are often executed sideways.

In some cultures, especially Hausa-Fulani, hugging a person of another sex may be considered extremely indecent. Therefore, in the workplace, proper deployment of such social non-verbal communication skills can be effective in transmitting peace.

\section{Conflict between what is communicated and what's perceived}

The content of communication may not be decoded with the meaning intended by the communicator. Kelly (2012) notes that there is a wide difference between what the communicator communicates verbally or non-verbally and what the decoder perceives.

It is not the act of displaying behaviors that directly affects psychological distance, but rather the perceptions of those behaviors. Therefore, the role of perception must be more carefully scrutinized and treated as a unique variable that mediates the actual behaviors of the message sender and the reaction of the message receiver.

In other words, the communicative behaviours people exhibit in the workplace derive their meaning mainly from the interpretation of the o recipients or communicate.

In view of the importance of workplace peace for productivity, the study investigated communication variables that university workers considered as important to workplace peace.

\subsection{Methodology}


In this study, we used a post-hoc survey inferential design. For data collection, a structured questionnaire was used. The questionnaire was labelled Workplace Peace Language Survey. It had four sections. Section A elicited demographic data while Section B required respondents to indicate the level to which they considered certain language variables like fluency, rich vocabulary, appropriate choice of words, and intonation, important to peace in their workplaces. In Section C, respondents were to indicate the extent to which they found non-verbal communication strategies important to workplace peace. In Section $\mathrm{D}$, the questionnaire required respondents to report how important to peace in the university were social interactions like attending colleagues' social events (birthdays, marriages, christening, etc) exchanging phone calls and emails, asking about one's wellbeing and chatting online. All participants received assurances of confidentiality, anonymity as well as their rights to withdraw from the study. There were 500 respondents. They were selected through purposive and snowball sampling.

\subsection{Research questions}

To guide the study, the researchers posed three research questions.

1. How important to peace in the workplace are verbal language components?

2. What non-verbal communication features do university workers consider important to workplace peace?

3. How important to peace in the workplace are social interactions?

4.0. Data analysis and presentation of results 
The questionnaires were retrieved and coded. Simple percentages were used to analyse the data and report the result. The following key should guide the reading of the tables:

$\mathrm{VI}=$ Very Important

$\mathrm{IM}=$ Important

$\mathrm{UM}=$ Unimportant

VU =Very Unimportant

$\mathrm{UN}=$ undecided

4.1. How important to peace in the workplace are verbal language components?

About 76 per cent of the respondents considered having a rich vocabulary as very unimportant to peace in the workplace. On the other hand, 26 per cent of the respondents considered appropriate diction as very important to peace in the workplace. On the average, only 10 per cent of the respondents considered as very important to workplace peace verbal components of English usage such as fluency, rich vocabulary, and appropriate choice of words, stress and intonation. The result is presented in Table 1.

Table 1. Importance of verbal language components to workplace peace

\begin{tabular}{|l|l|l|l|l|l|l|}
\cline { 2 - 7 } \multicolumn{2}{c|}{} & $\begin{array}{l}\text { VI } \\
(\%)\end{array}$ & $\begin{array}{l}\text { IM } \\
(\%)\end{array}$ & $\begin{array}{l}\text { UM } \\
(\%)\end{array}$ & $\begin{array}{l}\text { VU } \\
(\%)\end{array}$ & $\begin{array}{l}\text { UN } \\
(\%)\end{array}$ \\
\hline 1 & $\begin{array}{l}\text { Rich } \\
\text { vocabulary }\end{array}$ & $23(4.6)$ & $42(8.4)$ & $56(11.2)$ & $379(75.8)$ & $0(0)$ \\
\hline 2 & Fluency & $26(5.2)$ & $40(8)$ & $59(11.8)$ & $370(74)$ & $5(1)$ \\
\hline 3 & $\begin{array}{l}\text { Grammatical } \\
\text { correctness }\end{array}$ & $22(4.4)$ & $52(10.4)$ & $53(10.6)$ & $371(74.2)$ & $2(0.4)$ \\
\hline
\end{tabular}




\begin{tabular}{|l|l|l|l|l|l|l|}
4 & $\begin{array}{l}\text { Appropriate } \\
\text { choice of } \\
\text { words }\end{array}$ & $115(23)$ & $75(15)$ & $95(19)$ & $205(41)$ & $0(0)$ \\
\hline 5 & $\begin{array}{l}\text { Correct } \\
\text { Intonation } \\
\text { and stress }\end{array}$ & $70(14)$ & $60(12)$ & $275(55)$ & $95(19)$ & $0(0)$ \\
\hline
\end{tabular}

4.2. What non-verbal communication features do university workers consider important to workplace peace?

Regarding the importance of some non-verbal or paralinguistic communication variables to workplace peace, a great majority of respondents indicated that politeness (93\%), using words of endearment (87\%), greetings (76\%), smiling (70\%) and attentiveness (64\%) were very important to peace in the workplace. Giving a hug and handshake were considered unimportant by more than half the respondents. The result is presented in Table 2 . 
Table 2. The importance of nonverbal communication to workplace peace.

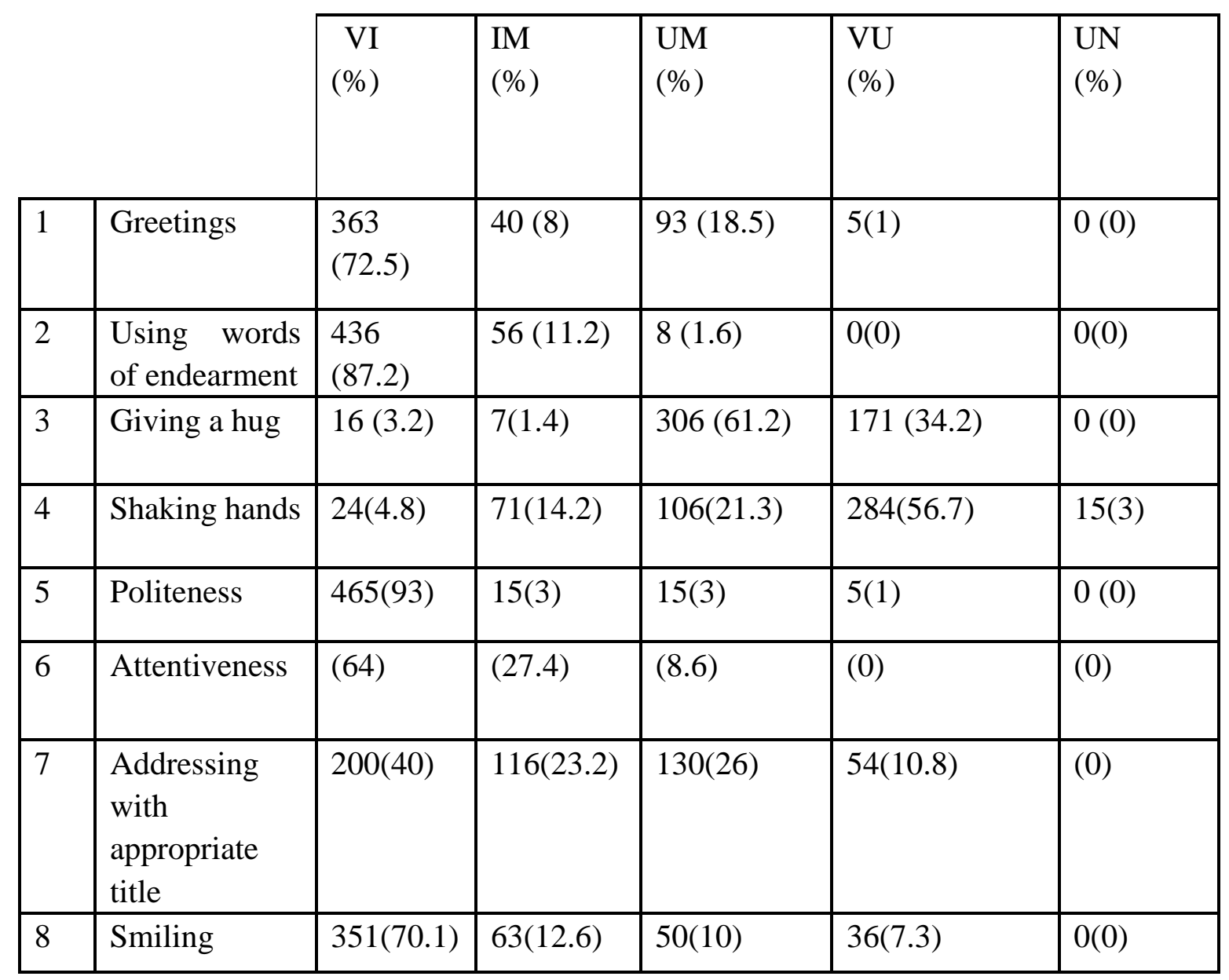

4.3. What social activities do university workers consider important to peace in the workplace?

In response to social activities that university workers considered important to peace in the workplace, nearly half of respondents considered exchanging visits as very important. What half the respondents considered very unimportant was online chatting. The result is presented in Table 3. 
Table 3. The importance of social interactions to peace in the university workplace.

\begin{tabular}{|c|c|c|c|c|c|c|}
\hline & & \\
\hline & & $\begin{array}{r}\mathrm{VI} \\
(\%)\end{array}$ & $\begin{array}{l}\mathrm{IM} \\
(\%)\end{array}$ & $\begin{array}{l}\mathrm{UM} \\
(\%)\end{array}$ & $\begin{array}{l}\mathrm{VU} \\
(\%)\end{array}$ & $\begin{array}{l}\mathrm{UN} \\
(\%)\end{array}$ \\
\hline 1 & $\begin{array}{l}\text { Exchanging phone } \\
\text { calls, and emails }\end{array}$ & $54(10.8)$ & $\begin{array}{l}261 \\
(52.2)\end{array}$ & $66(13.2)$ & $100(20)$ & $14(2.8)$ \\
\hline 2 & Online chatting & $40(8)$ & $75(15)$ & $127(25.4)$ & $258(51.6)$ & $0(0)$ \\
\hline 3 & $\begin{array}{l}\text { Wishing someone } \\
\text { happy birthday }\end{array}$ & $91(18.2)$ & $150(30)$ & $84(16.8)$ & $175(35)$ & $0(0)$ \\
\hline 4 & $\begin{array}{l}\text { Attending } \\
\text { colleagues, social } \\
\text { events }\end{array}$ & $\begin{array}{l}102 \\
(20.4)\end{array}$ & $\begin{array}{l}203 \\
(40.6)\end{array}$ & $156(31.2)$ & $35(7)$ & $4(0.8)$ \\
\hline 5 & Exchanging visits & $\begin{array}{l}226 \\
(45.2)\end{array}$ & $\begin{array}{l}102 \\
(20.4)\end{array}$ & $85(17)$ & $87(17.4)$ & $0(0)$ \\
\hline
\end{tabular}

\subsection{Discussion}

In this paper, we investigated the importance university workers attached to some verbal and non-verbal components of language. The result showed that non-verbal components of workplace communication and social interaction by workers were considered more important to peace in the workplace than verbal language dexterity. The findings are consistent with research that indicates that 80 per cent of all human communication is nonverbal (Merh

The findings further showed that of the non-verbal components of workplace communication the most important (93\%) was politeness. According to Weeks (2011), civility has to do with politeness, among others. Moreno Valley College (MVC) describes civility as the social norms and rules which people ought to follow so as to relate with others 
positively. MVC adds that civility conveys the idea of respect, courtesy, etc. it seems that human society, the university no less, value politeness or civility. One of the ways civility is $\begin{array}{llll}\text { expressed } & \text { is through }\end{array}$ "The seeds of civility can be planted in an organization by encouraging every employee to give their coworkers greetings befitting the professional nature of the work environment ." (Moreno Valley College, 2013, p.17).

Linguistic eloquence, grammatical accuracy and the effective or even near-native deployment of stress and intonation were not considered as germane to workplace peace. The supra-segmental elements are only evident in British or American English but are not prominent in the Nigerian variety of English. They are absent in indigenous Nigerian languages. Therefore, mere facility and proficiency in the use of English language may not necessarily translate into peace.

With regard to the research question on types of social interaction university workers value, the findings show that, on the average, about 50 per cent of the respondents considered exchanging visits, wishing someone happy birthday, attending colleagues' social events and exchanging phone calls and emails, as well as online chatting were very important to peace. Specifically, the largest percentage was allotted to exchanging of visits. In the Nigerian setting visiting someone at home or in the office denotes closeness and intimacy. The findings, therefore, cohere with the principle of immediacy as conceptualised by Mehrabian (1969). Mehrabian itemised components of immediacy to include eye contact, attentiveness, and closeness, among others. Online chatting was considered very unimportant to peace in the workplace. In today's ICT-driven world, online chatting is the rave amongst youths. 
Probably, it has not caught on sufficiently with the many University of Calabar faculty and staff. This may account for its perceived insignificance in workplace peace.

\subsection{Conclusions}

Peace speaks a unique language that is effective and affective. Within the University of Calabar academic community, where the lingua franca is English, language is not only the means of conducting business, it is the means of interacting and relating with one another at work. Language manifests as verbal and non-verbal. Since research shows that about 80 per cent of language used is nonverbal (Mehrabian, 1969), it is important to be acquainted with nonverbal communication components that are contextually related to peace in the workplace.

One of the nonverbal communication component that the majority reported as important was the smile. The findings agrees with Schoenmakers' (2014) view that a smile can lighten the workplace condition and create a friendly atmosphere. Moreover, since the findings indicated that 64 per cent of the respondents perceived attentiveness as a very important ingredient of workplace peace, it is prudent to heed UNESCO's counsel that "Respectful listening encourages respectful listening: if you want to be heard, listen" (p.17). The Bible cautions, "He who answers before listening, that is his folly and his shame" (Prov. 18:13).

\subsection{Recommendations}

Based on our findings we make the following recommendations:

1 Immediacy skills can be learned. It might be in the interest of institutions to provide immediacy training to their workers. Especially in the university, such training can equip both faculty and staff with the requisite relational skills for effective workplace 
peace negotiation.

2 Civility training may be required for both faculty and staff. As a follow-up, there should be a civility code in the university. The university rules and regulations are vague and silent about incivility amongst staff, faculty and students. Whether or not people behave civilly with one another should not be left to their whims. There should be documented civility expectations as well as sanctions for a breach so that civility can be seen as an institutional requirement and personnel responsibility.

Adejimola, A. S. (2009). Language and communication in conflict resolution. Journal of Law and Conflict Resolution 1(1), 001-009.

Aly, A. ,Brent, C. , Chihos, V., Clark, I., Ghaziri, M. E., Mansdorf, D., and Mishler, O.(2014). The civility discourse: Where do we stand and how do we proceed? University of Maryland, Baltimore.

Bicki, A. (2008). An Observation of Nonverbal Immediacy Behaviours of Native and Nonnative Lecturers. Journal of Social Sciences, 5(1),

Bowman, K. (2011). More than good manners: Cultivating a spirit of open dialogue and civility on campus. Public Purpose Magazine, Spring; (2) 6-9. Retrieved from http://www.aascu.org/uploadedFiles/AASCU/Content/Root/MediaAndPublicati ons/PublicPurposeMagazines/Issue/11spring_goodmanners.pdf.

Davetian, B. (2009). Civility: A cultural history. Toronto, ON: University of Toronto Eyang, A. (2016). Historical allusions as stylistic strategy in the poetry of Langston Hughes LWATI: A Journal of Contemporary Research 13 (2), 48-59 
Eyang, A. E. \& Edung, A. (2017). The Dynamics of Economism and Human Trafficking in Chika Unigwe's “On Black Sisters' Street” and Ifeoma Chinwuba’s "Merchants of Flesh”. LWATI: A Journal of Contemporary Research, 14 (2), 103-120

Forni, P.M. (2002). Choosing civility: The twenty-five rules of considerate conduct. New York, NY: St. Martin's.

Ghaith, G. M. and Shaban, K. A. (1994). Peace education in the ESL/EFL classroom: A framework for curriculum and instruction. TESL reporter 27(2), 56 - 62.

Heerey, E. A., \& Gilder, T. (2019). The subjective value of a smile alters social behaviour. PloS one, 14(12), e0225284. https://doi.org/10.1371/journal.pone.0225284

Houser, M. L., Horan, S. M., \& Furier, L. A. (2008). Dating in the fast lane: How communication predicts speed dating success. Journal of Social and Personal Relationships, 25, 749-768.

Kelly, S. E., (2012). "Examining the Role of Perceived Immediacy as a Mediator: Revisiting the Relationships among Immediate Behaviors, Liking, and Disclosure.” $\mathrm{PhD}$ dissertation, University of Tennessee, USA. Retrieved from http://trace.tennessee.edu/utk_graddiss/1414

Mehrabian, A. (1969). Some referents and measures of nonverbal behavior. Behavioral Research Methods and Instrumentation, 1, 213-217.

Moreno Valley College. (2013). Civility in the workplace: Training manual. Retrieved from www.mvc.edu/files/ep-civility-workplace.pdf

Rodríguez, C.M. (2006). Language diversity in the workplace. North western University Law Review. 100(4), 1690 - 1794. 
Rychlowska, M., Jack, R. E., Garrod, O., Schyns, P. G., Martin, J. D., \& Niedenthal, P. M. (2017). Functional Smiles: Tools for Love, Sympathy, and War. Psychological science, 28(9), 1259-1270. https://doi.org/10.1177/0956797617706082

Scales, S. (2010). Teaching civility in the age of Jerry Springer. Teaching Ethics, Spring

Schoenmakers, L. (2014). Happily different: Sustainable educational change - a relational approach. Chagrin Falls, Ohio, USA: Taos Institute Publications/WorldShare Books.

Timothy. A. E. (2017). Language and communication conflict in Nigeria: implications for English language pedagogy. Teacher Education and Curriculum Studies. 1(2), 4348.

Timothy, A. E. \& Uguma, V. U. (2017). Language civility, immediacy and peace valence among Nigerian university lecturers. LWATI. A Journal of Contemporary Research, 14(1).1-13.

Turman, P. D. (2008). Coaches' immediacy behaviors as predictors of athletes' perceptions of satisfaction and team cohesion. Western Journal of Communication, 72, 162179.

UNESCO Principal Regional Office for Asia and the Pacific. (1998).Learning to live together in peace and harmony; values education for peace, human rights, democracy and sustainable development for the Asia-Pacific region: a UNESCOAPNIEV E sourcebook for teacher education and tertiary level education. Bangkok: UNESCO PROAP.

Weeks, K. M. (2011). In search of civility: Confronting incivility on the college campus. 
Morgan James Publishing. 